\title{
Green Tourism Courses Customized with Digital Maps
}

\author{
Qiang YANG ${ }^{1, a}$, Jian $\mathrm{LI}^{1, \mathrm{~b},}$ and Xiaohui $\mathrm{ZOU}^{1,2 \mathrm{c}^{*}}$ \\ ${ }^{1}$ Sichuan Technology \& Business College, Chengdu, Sichuan \\ No. 8, Juyuan Section, Tianfu Avenue, Dujiangyan City, Sichuan Province 611830, China \\ ${ }^{2}$ Sino-American Searle Research Center (Berkeley \& Beijing) \\ a368490@qq.com, b 286722205@qq.com, 'email 949309225@qq.com \\ ${ }^{*}$ Corresponding author: Xiaohui ZOU
}

\begin{abstract}
Keywords: knowledge management, formatting digital map, knowledge graph, mind map
Abstract. This paper aims to introduce map knowledge management combined with personalization and standardization by taking the green tourism course as an example. The method is as follows: Firstly, the digital map knowledge management methods of the map of green tourism course are divided into several categories, namely: the first type is pure natural landscape, the second type is artificial landscape, and the third type is mixed landscape. Then, on the digital map customized by the green tourism course, these three types of landscapes are treated differently. Finally, the application of knowledge graphs and mind maps and other visualization techniques to enrich the personalized digital maps customized by the green tourism curriculum, and then find a series of events that can be standardized batch processing, and establish a smart query system. Its characteristics are: distinguish learning mode between large and small probability and very special exception. The result: not only the three types of landscapes are clearly visible in the digital map smart system customized by the green tourism course, but also the digital map knowledge management combined with personalized and standardized in the case of green tourism courses. The significance is that such a purpose, method and result not only help the teachers and students to better experience the innovative ideas of the green tourism curriculum, but more importantly, reserve enough opportunities for teachers and students to participate, for example, The selection and scoring of the three types of landscapes is a simple participation, and the effect will produce big data; for another example, not only can the standardized query be used, but also the personalized query can be conveniently established with examples in our paper.
\end{abstract}

\section{Introduction}

This article aims to customize personalized digital maps for green tourism courses. It is a prop, teaching aid and learning tool for the Green Tourism course. It is characterized by its ability to continuously complement the human intelligence and the artificial intelligence. The importance of maps and digital maps has long been verified and no longer has to be demonstrated. But how to construct a better map, especially a personalized digital map, that can be highly integrated with standardization is worthy of further study and discussion with the digital map knowledge management.

A method for making personalized electronic maps and their friendly interfaces has been proposed for several years. Now, it's time to further improve and optimize it. [1]

Digital image [2][3] and signal processing [4][5] as well as knowledge graphs [6][7] are all related to each other via software programming [8] [9].

The term and practice of software as a service have been around for some years. Software -as -a -service has been around for years. Especially with the rise of big data [11], data center [12] and data science [13], we are more concerned about how to better combine the following two aspects of intelligent system [14]. On the other hand, the majority of users (who are in urgent need of simplified smart systems including language, knowledge and software) can make up for the deficiency of a few experts(this paper focuses more on the new exploration of special smart system urgently needed by ordinary users and the direct application of the results). 


\section{Method}

The idea of any new method involves two parts: existing and innovative technologies. In other words, any invention has two parts: inheritance and innovation. This method is no exception.

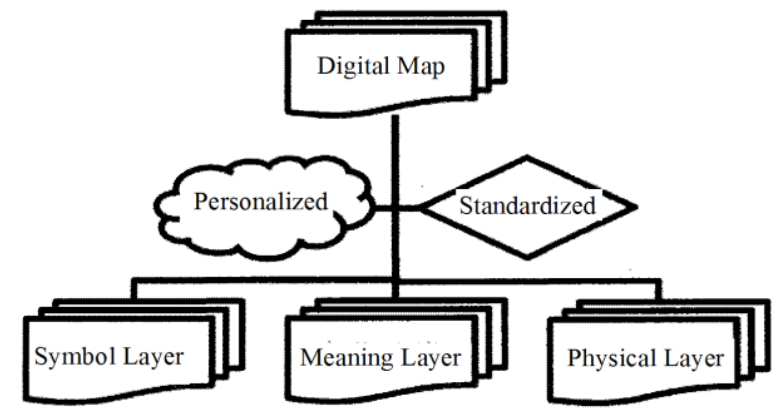

Figure 1 the basic principle of a hierarchical digital map [1]

It can be seen from Figure 1 that the hierarchical electronic \&digital map combined with personalization and standardization are characterized by the combination of the physical layer and the symbol layer for the formalization of the meaning layer (this is the two basic ways of how the user's inner thoughts are expressed). This research is a further development of the above method:

The method is as follows: Firstly, the digital image and signal processing methods of the green tourism course are divided into several categories, namely: the first type is pure natural landscape, the second type is artificial landscape, and the third type is mixed landscape. Then, on the digital map customized by the green tourism course, these three types of landscapes are treated differently. Finally, the application of knowledge graphs and mind maps and other visualization techniques to enrich the personalized digital maps customized by the green tourism curriculum, and then find a series of events that can be standardized batch processing, and establish a smart query system. Its characteristics are: distinguish learning mode between large probability, small probability and very special exception.

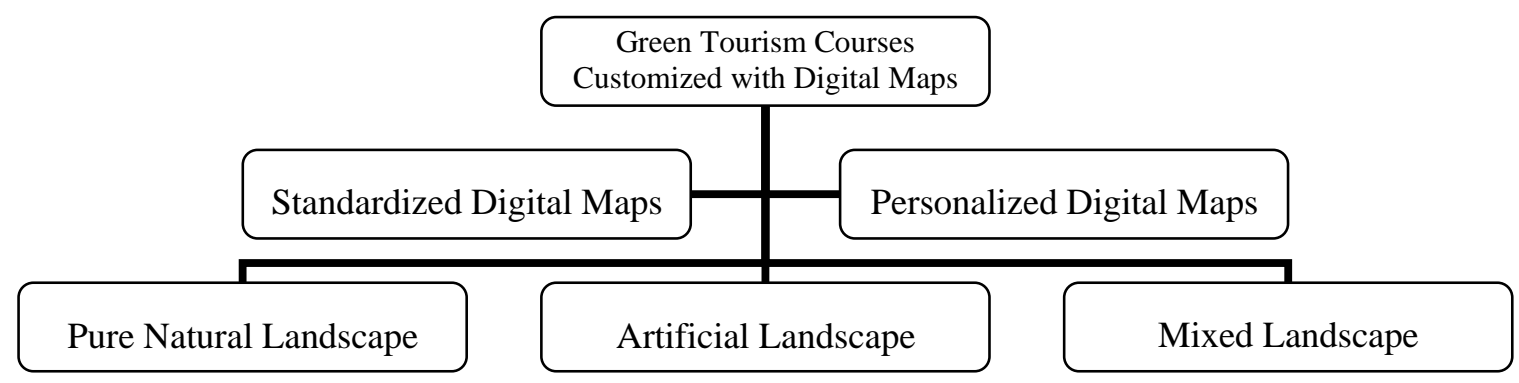

Figure 2 the green tourism courses customized with digital maps

It can be seen from Figure 2 that the green tourism course are divided into several categories.

Several Categories Divided The In the aspect of software as a service, the classification of users' actual needs is not only the expertise of a few human expert users, but also the expertise of a large number of ordinary users. With the help of the smart system, almost all users can learn from themselves in terms of actual requirements (especially the rigid requirements in real scenarios) (depending on whether the smart system software used at this time is smart enough).

Firstly, the methods of the electronic \&digital map for green tourism course are divided into several categories, namely: the first type is pure natural landscape, the second type is artificial landscape, and the third type is mixed landscape for the physical layer. Whether it is $2 \mathrm{D}$ or 3D electronic \& digital maps, it can be physically divided by object-oriented software programming. Thus, people looking at or reading a picture can customize a personalized \& standardized n-dimensional electronic \& digital map according to their respective purposes, wishes and goals. 
For example, I am going to Oxford University to attend an international academic conference. The goal is clear to fly from Beijing (Capital International Airport) to London (Heathrow International Airport), then from London to Oxford (metro or light rail train), and finally to the Oxford University (nearly hotel). The above electronic map recording of London, Britain is far from satisfying my needs (I really want a privately-designed digital map for this international trip, but I don't have a ready-made one, I have to make it myself, for the time being, not to mention how many users want to have their own private personalized digital maps). Furthermore, I may also wish to take a look at the weather and temperature I arrived in the UK. These are only geographical information about natural landscapes. It's not a problem with current technology offering them. However, so far, there is no series of basic function keys (especially special smart maps that can realize human-machine dialogue) that can be customized to personalize digital maps.

There is only a lot of content in the red box that can be displayed hierarchically in batches according to the actual needs of the user. However, it is not only not have it, but also there are a lot of content that has nothing to do with the specific user, that is, it is not needed at all (not to mention the red box, but there are too many content information that the user does not need in the red box)! Why not make a layered form that allows them to reuse? For another example, I only care about the logo and roadmap of the artificial infrastructure such as the subway or light rail train from Heathrow International Airport to London (it only needs to add a few function keys to embed the relevant links to achieve many Customized service!).

As another example, I am only concerned with the signs and road maps of the artificial infrastructure such as subway or light rail trains from Heathrow International Airport to London and then to Oxford and the iconic natural landscape along the way. With the help of computer graphics and visualization technology, these are not difficult to achieve. Why have not been able to do so for so many years? Answering this question leads to a private custom digital map!

Digital Map Customized Personally customized personalized digital maps are based on standardized digital maps. To illustrate this truth, we introduce a complementary principle of the formal understanding model that corresponds to the basic principles of the hierarchical digital map described in Figure 1, as a macroscopic formal understanding model (the principle of the Tao function) ${ }^{1}$

The original view, through geometric algebra continuous transformation, is transformed from human brain into a machine simulation architecture that can be understood and executed by computer (laying a solid theoretical foundation for software programming modeling and computer simulation interpretation).

Enrich Personalized Maps Finally, the application of knowledge graphs and mind maps and other visualization techniques to enrich the personalized digital maps customized by the green tourism curriculum, and then find a series of events that can be standardized batch processing, and establish a smart query system.

It can be seen from that the basic division of the two road routes from Heathrow Airport to Greenwich and Oxford. Such a sketch can be directly highlighted from digital, informative and intelligent maps (including subway and railroad) for us to make it simple and using simple for the complicated that don't have to paint by user. Our design idea is this: simplifying and planning in a bidirectional classification. The traffic radius of international aviation, intercontinental \& local railways and urban subways (artificial landscapes) and people walking (viewing natural and artificial and mixed landscapes) vary greatly. Therefore, it is entirely possible to simplify the point-to-point travel route map from macro, meso and micro perspectives (without having to be within the line of sight of the target). For example, not only the contents of figures 2 to 4 but also the road maps for

\footnotetext{
${ }^{1}$ How to copy it from human brain to computer that is a Figure in the Formal Understanding Models at International Conference on Cognitive Systems and Information Processing ICCSIP 2018.

http://bbs.sciencenet.cn/home.php?mod=attachment\&filename=Agenda_1126\%D0\%C2\%D0\%DE\%B8\%C4\%B0\%E6-1.pdf\&id=286 857
} 
underground are implicit in the back of figure 6 in London. In other words, they can actually be displayed multiple times according to the user's individual needs (without having to be like a normal map, or want to label, or always miss a lot of the knowledge, information or data provided), each only need to highlight the necessary content related to a certain target (no more, just right).

\section{Result}

The result: not only the three types of landscapes are clearly visible in the digital map smart system customized by the green tourism course, but also the digital image and signal processing combined with personalized and standardized in the case of green tourism courses.

As a result of this, not only the target is clear, the key targets are Heathrow Airport, Greenwich and Oxford (others are not required), and the three intermediate transfer stations are also marked with clear even, it will bring a series of relevant knowledge, information and data that can be expressed in different levels. The most important thing is that the teachers and students of the green tourism course can participate in the digitalization of such hierarchical maps and the intelligent construction of systems engineering (social system engineering combining education, management, learning and use; formal system engineering combining language, knowledge, software and hardware).

Green tourism or ecotourism has been proposed for many years. In fact, it is caused by the conflict between industrial society and agricultural society (mainly a series of problems caused by the destruction of the environment and ecology caused by the industrialization process, and a series of garbage damaging the ecological environment caused by the tourism population and its industrial supplies, especially its packaging materials).

Green or ecological as the attributive word of tourism, the combination concept "green tourism" is becoming more and more popular because people like to use this concept to encourage or commend the way to promote the rural environment in favor of rather than harm the natural environment. Leisure activities Arwel Jones, a tourism \& environmental consultant that year, described the conference on the topic, which explored a strategic approach to sustainable and excellent ecological care for the future. [15]

Opportunity to enhance reputation of the environment by visiting visitors to promote their green credit, the visitor centre of the Scottish Malt Whisky Distillery is used as a type of industrial tourist attraction. This research can enhance its environmental credibility and facilitate the popularization of green tourism. [16]

Whilst the term "green economy" can have many interpretations, here it refers to the global strategy framework surrounding RIO +20 , as well as the policies and strategies being developed by tourism destinations as a response. [17] A model of recreational visitor behavior with an ecological model estimates the impact of the increased visitors upon the environment. [18] This provides an overview of the interrelationships between tourism and sustainability from a cross-disciplinary perspective. [19]

Our study of green tourism curriculum considered three major sectors, namely: green tourism overview with its terminology framework and method architecture, practicing green tourism and experiencing green tourism both are inseparable from the digital map described in this paper, that is: through the three categories of layered as shown in figure 1 and achieve a series of annotations to achieve the compatibility of personalization and standardization. First, introducing a statistical-based machine learning method to deal with large probability events, secondly, introducing a human-computer interaction interface technology to deal with small probability events, and third, introducing an expert knowledge acquisition technique to deal with special exceptions. It is characterized by a combination of three approaches, focusing on the interdisciplinary, cross-domain and cross-industry smart system construction, and converging to the knowledge module of the green tourism curriculum. 


\section{Discussion}

What is green tourism? We first use statistical-based literature analysis methods to examine the development trends of the research in this field and related aspects, and get the following set of results:

It can be seen from that although the trend graph of the research topic of green tourism is ups and downs, its overall trend is on the rise. This at least shows that academic attention to the concept of green tourism has been steadily developing since 1998. With the How-Net big data using, researchers can get instantly publish trends from 1990 to 2018. This is a strong support of technology for education and research. If you do the same thing with human resources, then the efficiency will be very low.

As can be seen from the green curve (the longest, ie 1956 to 2018) is all references to the green tourism theme, and the right side is steep the orange curve (ie 2015 to 2018) is the subject of our attention and citation. Unconsciously statistical-based machine learning has long been a substitute for statisticians' intellectual work. Based on this researcher and teachers and students can do similar survey statistics and comparative analysis on any topic keywords of their own concern. With such an analysis tool, we have a good foundation for the teaching and research work of the introduction of green tourism. The rest of the work is a reasonable division of labor between people and humans and a high degree of cooperation. Collaborate on the verification and compilation of basic terms and the collection and processing of knowledge graph.

\section{Conclusion}

Its main role, value and significance are:

Through a series of seemingly insignificant practical requirements, the visualization method is directly adopted, such as adding corresponding links or function keys (making it similar to the smart system with one-click effect) on the digital map, which reflects the unique effect of hierarchical map. Just think: if the user interface of man-machine interaction in the hands of tourists is simplified as shown in figure 1 and figure 6 , how convenient the travel will be!

It has not only economic value (immediate impact) but also social value (sustainable development).

Its significance lies not in the actual work and social and economic value, also lies in its culture, science and technology, education and management, and other aspects of significance, because, no longer just a handful of experts can be well into the language, knowledge, and these three kinds of multifarious software engineering techniques involved in the modeling and simulation in the field of human-computer interaction, and the average of the teachers and students also can use smart system rapidly and sustainably on his involvement in the familiar "modeling and simulation in the field of the past so only a few experts can only do the man-machine interaction, such as: language ambiguity search and resolution, and such as: analysis of the concept of knowledge and polishing, such as: Description and modeling of software requirements.

\section{Acknowledgment}

This work was supported by the Joint Project of Sino-American Searle Research Center in China (Grants No. 2018-2019-01b).

\section{References}

[1] Zou Shunpeng, Zou Xiaohui. 2011. A method for making personalized electronic maps and their friendly interfaces: China, CN201010175303.9[P].2011-11-23.

[2] Gonzalez, R. C., \& Wintz, P. 2008. Digital image processing. Prentice Hall International, 28(4), 484 - 486. 
[3] Corr, D., Accardi, M., Graham-Brady, L., \& Shah, S. 2016. Digital image correlation analysis of interfacial debonding properties and fracture behavior in concrete. Engineering Fracture Mechanics, 74(1), 109-121.

[4] Rioul, O. , \& Vetterli, M. . 1991. Wavelets and signal processing. IEEE Signal Processing Magazine, 8(4), 14-38.

[5] Perraudin, N. , \& Vandergheynst, P. . 2017. Stationary signal processing on graphs. IEEE Transactions on Signal Processing, 1-1.

[6] Shi, B. , \& Weninger, T. . 2016. Discriminative predicate path mining for fact checking in knowledge graphs. Knowledge-Based Systems, 104, 123-133.

[7] Jayaram, N. , Khan, A. , Li, C. , Yan, X. , \& Elmasri, R. . 2015. Querying knowledge graphs by example entity tuples. IEEE Transactions on Knowledge and Data Engineering, 27(10), 1-1.

[8] Hermans, F. , Siegmund, J. , Fritz, T. , Bavota, G. , Nagappan, M. , \& Hindle, A. , et al. 2016. Leaders of tomorrow on the future of software engineering: a roundtable. IEEE Software, 33(2), 99-104.

[9] Arasteh, B., \& Najafi, J. 2018. Programming guidelines for improving software resiliency against soft-errors without performance overhead. Computing (2), 1-33.

[10]Childers, L., \& Foster, I. 2012. Software as a service for data scientists. Communications of the Acm, 55(2), 81-88.

[11]Xu, X., Motta, G., Tu, Z., Xu, H., Wang, Z., \& Wang, X. 2018. A new paradigm of software service engineering in big data and big service era. Computing, 100(4), 353-368.

[12]Liu, S., \& Li, B. (2017). Stemflow: software-defined inter-datacenter overlay as a service. IEEE Journal on Selected Areas in Communications, PP(99), 1-1.

[13]Dhar, V. (2013). Data science and prediction. Communications of the Acm, 56(12), 64-73.

[14] Nedjah, N., Wyant, R. S., Mourelle, L. M., \& Gupta, B. B. (2017). Efficient fingerprint matching on smart cards for high security and privacy in smart systems. Information Sciences, S0020025517311611.

[15] Jones, A. . 1987. Green Tourism. Tourism Management, 8(4), 354-356.

[16] Mcboyle, G. . 1996. Green Tourism and Scottish Distilleries. Tourism Management, 17(4), 255-263.

[17]Law, A., Delacy, T., \& Mcgrath, G. M. 2017. A green economy indicator framework for tourism destinations. Journal of Sustainable Tourism (4), 1-22.

[18]Pan, S. Y., Gao, M., Kim, H., Shah, K. J., Pei, S. L., \& Chiang, P. C. 2018. Advances and challenges in sustainable tourism toward a green economy. Science of the Total Environment, 635, 452-469.

[19]Dvarskas, A. 2017. Dynamically linking economic models to ecological condition for coastal zone management: application to sustainable tourism planning. Journal of Environmental Management, 188, 163-172. 